\title{
PENGARUH KOMUNIKASI PEMASARAN TERHADAP KEPUTUSAN MEMBELI BUKU OLEH MASYARAKAT PADA GRAMEDIA BANJARMASIN VETERAN
}

\author{
Margareta Krissa Delima ${ }^{1)}$ Muhammad Agus Humaidi $^{2)}$
}

Universitas Islam Kalimantan Muhammad Arsyad Al-Banjari Banjarmasin

\begin{abstract}
ABSTRAK
Penelitian ini bertujuan untuk mengetahui komunikasi pemasaran dan keputusan membeli buku leh masyarakat pada Gramedia Banjarmasin Veteran, selain itu untuk mengetahui pengaruh antara komunikasi pemasaran terhadap keputusan membeli buku oleh masyarakat pada Gramedia Banjarmasin Veteran. Metode yang digunakan adalah pendekatan penelitian kuantitatif dan instrumen penelitian dengan koesioner yang dianalisis dengan Chi Square Goodness Of Fit dan Regresi Linier Sederhana. Hasil penelitian menunjukan bahwa komunikasi pemasaran pada Gramedia Banjarmasin Veteran termasuk kategori baik. Sedangkan keputusan membeli buku oleh masyarakat termasuk kategori sangat baik. Selain itu terdapat pengaruh signifikan antara komunikasi pemasaran terhadap keputusan membeli oleh masyarakat pada Gramedia Banjarmasin Veteran.
\end{abstract}

Kata Kunci: Komunikasi Pemasaran;Keputusan Membeli.

antara iklan, penjualan personal, promosi penjualan, hubungan masyarakat, dan pemasaran langsung yang digunakan perusahaan untuk meraih tujuan pemasarannya.

Memperbaiki dan mempertahankan hubungan antara perusahaan dengan pelanggannya perlu terus dibina. Sehubungan dengan itu, yang harus dilakukan perusahaan adalah menyusun strategi komunikasi pemasaran yang efektif dan mengimplementasikannya dengan serius. Tujuannya yaitu untuk mengenalkan keunggulankeunggulan dari suatu produk kepada konsumen, sehingga produk tersebut memperoleh perhatian dari konsumen. Komunikasi pemasaran terpadu (integrated marketing communication) merupakan konsep perencanaan komunikasi pemasaran yang mengakui nilai tambah rencana yang komprehensif (Kotler, 2005:12).

Aspek pemasaran tidak hanya mengarah pada fungsi produk saja, namun akan lebih fokus pada pertempuran promosi atau berkomunikasi dengan pasar. Perusahaan berlomba-lomba menciptakan komunikasi yang unik agar produknya dapat diterima atau setidaknya dikenal oleh masyarakat.

Akibat dari hal tersebut, konsumen memiliki kecenderungan untuk memilih produk mana yang akan dikonsumsi dan mana yang tidak. Perubahan tersebut berpengaruh pada perilaku pembelian konsumen terhadap kebutuhan mereka, baik primer maupun sekunder. Menurut Umar (2005:67) mengemukakan bahwa perilaku konsumen sangat menentukan dalam proses pengambilan keputusan membeli yang tahapnya dimulai dari pengenalan masalah, yaitu berupa 
desakan yang membangkitkan tindakan untuk memenuhi dan memuaskan kebutuhannya.

Komunikasi pemasaran tampaknya memiliki pengaruh terhadap keputusan membeli hal ini dapat diketahui dari hasil penelitian dari Meriza Hendri (2009) menyatakan bahwa komunikasi pemasaran bepengaruh terhadap keputusan pembelian teh kotak rasa melati leh remaja di Kota Bandung. Selain itu dari hasil penelitian Bintoro, Ahyar Yuniawan dan I Made Sukresna (2016) menyatakan bahwa terdapat pengaruh antara komunikasi pemasaran terhadap keputusan pembelian pada produk bubur bayi promina di Carrefour Wilayah Jakarta Selatan. Serta Dinda Anggraeni (2017) dalam hasil penelitiannya menemukan bahwa komunikasi pemasaran berpengaruh signifikan terhadap keputusan pembelian produk pada Dealer Mpm Motor Pare.

Gramedia Asri Media merupakan anak perusahaan Kompas Gramedia yang menyediakan jaringan toko buku dengan nama Toko Buku Gramedia. Toko buku Gramedia Banjarmasin didirikan pada tahun 1997 dan perusahaan ini bekerjasama dengan penerbit-penerbit buku baik dalam maupun luar negeri. Selain dari penjualan buku, Toko Buku Gramedia juga menyediakan produk lain seperti alat tulis/keperluan sekolah, pelengkapan kantor, alat olahraga, alat musik, jam tangan dan lainnya. Hal tersebut merupakan cara untuk memaksimalkan dalam memberikan pilahan kebutuhan kepada masyarakat untuk mengambil keputusan membeli di Toko Buku Gramedia Banjarmasin namun hal ini perlu didukung dengan komunikasi pemasaran yang baik kepada pelanggan.

Peneliti tertarik untuk melakukan penelitian "Pengaruh komunikasi pemasaran terhadap keputusan membeli buku oleh masyarakat pada Gramedia Banjarmasin Veteran", karena selama observasi dalam melakukan penelitian pada Gramedia Banjarmasin Veteran, penulis menemukan beberapa gejala atau fenomena seperti masih kurangnya komunikasi yang efektif antara penjual dengan pelanggan dalam hal ini untuk memberikan penjelasan mengenai buku terbitan baru yang ada pada Gramedia Banjarmasin Veteran untuk dibeli masyarakat. Selain itu aktifitas promosi penjualan untuk mendorong pembelian sebuah produk juga jarang diadakan. Dari beberapa hal tersebut, dapat diasumsikan bahwa jalinan komunikasi pemasaran antara perusahaan dengan pelanggan belum begitu baik dan penerapan komunikasi pemasaran pada Gramedia Banjarmasin Veteran nampaknya belum berjalan secara optimal.

\section{TINJAUAN PUSTAKA}

\section{Komunikasi Pemasaran}

Komunikasi pemasaran menurut Kotler dan Keller (2008:172) merupakan sarana dimana perusahaan berusaha menginformasikan, membujuk, dan mengingatkan konsumen secara langsung maupun tidak langsung tentang produk dan merek yang dijual. Sedangkan Menurut Mamang (2013:225) mengemukakan bahwa komunikasi pemasaran adalah komunikasi yang dilakukan antara produsen, perantara, pemasaran, dan konsumen, dan merupakan kegiatan untuk membantu konsumen mengambil keputusan di bidang pemasaran serta mengarahkan pertukaran atau transaksi agar lebih memuaskan dengan menyadarkan semua pihak untuk berpikir, berbuat, dan bersikap lebih baik.

Dalam penelitian ini digunakan pendapat dari Basu dan Irawan (2000:271-278) untuk mengukur komunikasi pemasaran pada Gramedia Banjarmasin Veteran, antara lain : 1) Periklanan; 2) Promosi penjualan; 3) Publisitas dan 4) Penjualan langsung.

\section{Keputusan Membeli}

Pengertian keputusan pembelian, menurut Kotler \& Armstrong (2008: 181) adalah tahap dalam proses pengambilan keputusan pembeli di mana konsumen benar-benar membeli. Sedangkan menurut Suharno (2010:96) keputusan pembelian merupakan tahap dimana pembeli telah menentukan pilihannya dan melakukan pembelian produk, serta mengkonsumsinya.

Dalam penelitian ini digunakan pendapat dari Kotler dan Keller dalam Tjiptono untuk mengukur keputusan membeli pada Gramedia Banjarmasin Veteran, antara lain : 1) Pilihan produk ; 2) Pilihan merek; 3) Pilihan penyalur; 4) Waktu pembelian dan 5) Jumlah pembelian.

\section{Pengaruh Komunikasi Pemasaran terhadap Keutusan Membeli}

Dasar atau acuan yang berupa teori-teori atau temuan-temuan melalui hasil berbagai penelitian sebelumnya merupakan hal yang sangat perlu dan dapat dijadikan sebagai data pendukung. Salah satu data pendukung yang menurut peneliti perlu dijadikan bagian tersendiri adalah penelitian terdahulu yang relevan dengan permasalahan yang sedang dibahas dalam penelitian ini. Dalam hal ini, fokus penelitian terdahulu yang dijadikan acuan adalah terkait dengan pengaruh komunikasi pemasaran terhadap keputusan membeli. Oleh karena itu, peneliti melakukan langkah kajian terhadap beberapa hasil penelitian berupa jurnaljurnal melalui internet. Berdasarkan hasil-hasil penelitian yang telah dilakukan menyiratkan bahwa variabel komunikasi pemasaran berpengaruh 
terhadap keputusan membeli seperti hasil penelitian sebagai berikut:

Meriza Hendri (2009) meneliti tentang pengaruh komunikasi pemasaran terhadap keputusan pembelian teh kotak ultra rasa melati oleh remaja di Kota Bandung, hasil penelitian menunjukankomunikasi pemasaran berpengaruh terhadap keputusan pembelian Teh Kotak Ultra rasa melati oleh remaja di Kota Bandung, terbukti Berdasarkan hasil penghitungan pada tabel anova nilai signifikan $0,000<$ dari taraf kesalahan $(\alpha)=$ 0,05 sehingga $\mathrm{H}_{0}$ ditolak dan $\mathrm{H}_{1}$ diterima.

Selain itu penelitian dari Bintoro, Ahyar Yuniawan dan I Made Sukresna (2016) tentang pengaruh komunikasi pemasaran, kepercayaan merek dan ekuitas merek terhadap keputusan pembelian (Studi pada Produk Bubur Bayi Promina di Carrefour Wilayah Jakarta Selatan), hasil penelitian menunjukan variabel komunikasi pemasaran terhadap keputusan pembelian dengan nilai probabilitas sebesar 0,000 . Nilai probabilitas $=$ 0,000 lebih kecil dari 0,05 menandakan bahwa komunikasi pemasaran memiliki pengaruh positif dan signifikan terhadap keputusan pembelian.

Serta penelitian dari Dinda Anggraen (2017) tentang pengaruh komunikasi pemasaran, kelengkapan produk dan fasilitas terhadap keputusan pembelian pada Dealer Mpm Motor Pare, Berdasarkan nilai sig. variabel komunikasi pemasaran adalah sebesar $0,040<0,05$, nilai tersebut lebih kecil dari $\alpha=0.05$, sehingga hipotesis Ha diterima yang artinya semakin baik komunikasi pemasaran digunakan perusahaan, maka menjadikan Dealer MPM Motor Pare untuk melakukan keputusan pembelian.

Dari hasil penelitian diatas, maka dapat ditarik kesimpulan bahwa dengan adanya komunikasi pemasaran yang baik maka dapat meningkatkan keputusan membeli oleh masyarakat. Begitu juga sebaliknya, jika komunikasi pemasaran kurang baik maka keputusan membeli oleh masyarakat pun juga akan ikut menurun. Jadi dengan kata lain komunikasi pemasaran akan berpengaruh terhadap keputusan membeli oleh masyarakat.

\section{Kerangka Berfikir}

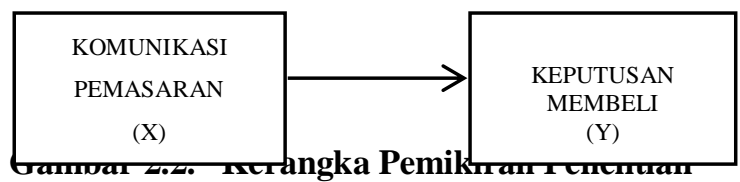

Komunikasi Pemasaran (X) sebagai variabel independen (variabel bebas) mempengaruhi variabel dependen (variabel terikat) Keputusan Membeli (Y).

5. Hipotesis

Pengaruh Komunikasi Pemasaran terhadap Keputusan Membeli
$\mathrm{H}_{0}$ : Tidak terdapat pengaruh yang signifikan antara Komunikasi Pemasaran terhadap Keputusan Membeli buku oleh masyarakat pada Gramedia Banjarmasin Veteran.

$\mathrm{H}_{1}$ : Terdapat pengaruh yang signifikan antara Komunikasi Pemasaran terhadap Keputusan Membeli buku oleh masyarakat pada Gramedia Banjarmasin Veteran.

\section{METODE PENELITIAN}

\section{Pendekatan Penelitian}

Dalam melakukan penelitian ini penulis memilih jenis penelitian kuantitatif dengan pendekatan survey.

\section{Tipe Penelitian}

Penulis dalam penelitian ini menggunakan metode penelitian deskriptif dan assosiatif.

\section{Lokasi Penelitian}

Penelitian ini dilakukan pada Gramedia Banjarmasin Veteran dengan objek mencakup Pengaruh antara komunikasi pemasaran terhadap keputusan membeli buku oleh masyarakat pada Gramedia Banjarmasin Veteran.

\section{Populasi dan Sampel}

Populasi dalam penelitian ini adalah seluruh masyarakat yang membeli buku pada Gramedia Banjarmasin Veteran. Dalam penelitian ini populasi tidak diketahui jumlahnya. Menurut Wibisono dalam Riduwan dan Akdon (2013), rumus dalam menghitung sampel pada populasi yang tidak diketahui adalah sebagai berikut:

$$
\begin{aligned}
& \mathrm{N}=\left\{\frac{((\mathrm{Za} / 2) \cdot \sigma)}{\mathrm{e}}\right\}^{2} \\
& \mathrm{~N}=\left\{\frac{(1.96 \cdot 0.25)}{5 \%}\right\}^{2} \\
& \mathrm{~N}=96,04 \text { dibulatkan } 100
\end{aligned}
$$

Dimana :

$\mathrm{N} \quad=$ jumlah sampel

$\mathrm{Za} / 2$ = nilai dari tabel distribusi normal

atas tingkat keyakinan $95 \%=1,96$.

$\sigma \quad=$ standar deviasi $25 \%$

e $\quad=$ error $($ batas kesalahan $=5 \%$ )

Batas kesalahan atau margin of error dalam penelitian ini adalah 5\% (0,05), sehingga tingkat akurasinya sebesar 95\%. Sampel yang diambil untuk mengisi kuesioner sebanyak 100 responden. Skala yang digunakan dalam penelitian ini adalah Skala Likert.

\section{Teknik Pengumpulan Data}

Untuk memperoleh pada Gramedia Banjarmasin Veteran khususnya data primer maka dalam penelitian ini digunakan teknik pengumpulan dengan kuesioner (angket)

\section{Definisi Operasional Variabel}


Untuk memperjelas definisi operasional variabel tersebut, peneliti membuat tabel dimana dalam tabel tersebut terdapat bagian kolom variabel, indikator dan parameter. Berikut tabel 3.2. dapat dilihat dibawah ini :

Tabel 3.2. Definisi Operasional Variabel

\begin{tabular}{|c|c|c|}
\hline Variabel & Indikator & Parameter \\
\hline \multirow{4}{*}{$\begin{array}{l}\text { Komunikasi Pemasaran adalah } \\
\text { merupakan suatu sarana yang digunakan } \\
\text { oleh perusahaan dalam } \\
\text { menginformasikan dan membujuk serta } \\
\text { mengingatkan konsumen tentang produk } \\
\text { yang mereka jual dan ditujukan untuk } \\
\text { performance pemasaran. }\end{array}$} & Periklanan & $\begin{array}{l}\text { - Media iklan } \\
\text { - Frekuensi penayangan }\end{array}$ \\
\hline & Promosi penjualan & $\begin{array}{l}\text { - Harga Terjangkau } \\
\text { - Program undian } \\
\text { - Diskon prooduk } \\
\end{array}$ \\
\hline & Publisitas & $\begin{array}{l}\text { - Pemberitahuan di surat kabar } \\
\text { - Citra Baik } \\
\text { - Kegiatan Penggalangan dana }\end{array}$ \\
\hline & Penjualan langsung & $\begin{array}{l}\text { - Kemampuan karyawan } \\
\text { - Penampilan karyawan }\end{array}$ \\
\hline \multirow{5}{*}{$\begin{array}{l}\text { Keputusan Membeli merupakan suatu } \\
\text { proses pengambilan keputusan konsumen } \\
\text { yang telah telah menentukan pilihannya } \\
\text { dan melakukan pembelian produk, serta } \\
\text { mengkonsumsinya. }\end{array}$} & Pilihan produk & $\begin{array}{l}\text { - Ragam varian produk } \\
\text { - Kualitas produk }\end{array}$ \\
\hline & Pilihan merek & $\begin{array}{l}\text { - Kepercayaan penerbit } \\
\text { - Popularitas penerbit }\end{array}$ \\
\hline & Pillihan penyalur & $\begin{array}{l}\text { - Kemudahan mendapatkan produk } \\
\text { - Ketersedian produk }\end{array}$ \\
\hline & Waktu pembelian & $\begin{array}{l}\text { - Pembelian Ulang } \\
\text { - Pembelian dalam waktu } \\
\text { bersamaan } \\
\end{array}$ \\
\hline & Jumlah pembelian & - Pembelian produk lebih dari satu \\
\hline
\end{tabular}

\section{Analisa Data}

Untuk menjawab rumusan masalah pertama maupun kedua, sekaligus menjawab hipotesis komunikasi pemasaran dan keputusan membeli dalam penelitian ini menggunakan rumus Chi Square Goodness Of Fit. Sedangkan untuk menjawab rumusan masalah ketiga mengenai pengaruh komunikasi pemasaran terhadap keputusan membeli digunakan statistik Regresi Linier Sederhana.

HASIL PENELITIAN DAN PEMBAHASAN

1. Komunikasi Pemasaran

Tabel 4.26. Komunikasi Pemasaran

\begin{tabular}{clcc}
\hline No. & Keterangan & F & \% \\
\hline 1. & Sangat Baik & 3 & 3,0 \\
2. & Baik & 48 & 48,0 \\
3. & Cukup Baik & 42 & 42,0 \\
4. & Kurang Baik & 6 & 6,0 \\
5. & Tidak Baik & 1 & 1,0 \\
\hline & Jumlah & 100 & 100,0
\end{tabular}

Sumber: Analisa Data Primer 2019
Dari tabel 4.26. tersebut, ternyata kesimpulan disemua kategori komunikasi pemasaran pada Gramedia Banjarmasin Veteran, menunjukan bahwa komunikasi pemasaran pada Gramedia Banjarmasin Veteran Baik.

\section{Keputusan Membeli}

Tabel 4.27. Keputusan Membeli

\begin{tabular}{clcc}
\hline No. & Keterangan & F & \%, \\
\hline 1. & Sangat Baik & 34 & 34,0 \\
2. & Baik & 23 & 23,0 \\
3. & Cukup Baik & 17 & 17,0 \\
4. & Kurang Baik & 16 & 16,0 \\
5. & Tidak Baik & 10 & 10,0 \\
\hline & Jumlah & 100 & 100,0 \\
\hline
\end{tabular}
Sumber: Analisa Data Primer 2019

Dari tabel 4.27. tersebut, ternyata kesimpulan disemua kategori keputusan membeli buku oleh masyarakat pada Gramedia Banjarmasin Veteran, menunjukan bahwa keputusan membeli buku oleh masyarakat pada Gramedia Banjarmasin Veteran Sangat Baik.

\section{Pengaruh Komunikasi Pemasaran terhadap Keputusan Membeli}


MUTAKALLIMIN; Jurnal Ilmu Komunikasi

Vol 3 No 1 Mei 2020

Tabel 4.29. Pengaruh Komunikasi Pemasaran terhadap Keputusan Membeli

Coefficients $^{\mathrm{a}}$

Unstandardized Coefficients

\begin{tabular}{llr}
\multicolumn{2}{l}{ Model } & \multicolumn{1}{c}{ B } \\
\hline 1 & (Constant) & 29,629 \\
\cline { 2 - 3 } & Komunikasi Pemasaran &, 289 \\
\hline \multicolumn{2}{l}{ a. Dependent Variable: Keputusan Membeli } \\
& Sumber: Peneliti, Output SPSS 24, 2019
\end{tabular}

Pada tabel 4.29. di atas, dapat diketahui nilai signifikansi untuk pengaruh variabel $\mathrm{X}$ tehadap variabel $\mathrm{Y}$ adalah sebesar 0,011 yang lebih kecil dari 0,05 sehingga dapat disimpulkan bahwa hipotesis dalam penelitian ini dapat diterima yaitu terdapat pengaruh signifikan antara komunikasi pemasaran terhadap keputusan membeli buku oleh masyarakat pada Gramedia Banjarmasin Veteran. Selain itu, berdasarkan nilai thitung adalah 2,580 sedangkan t tabel 1,984 karena t hitung dari variabel tersebut lebih besar dari t tabel, sehingga dapat disimpulkan bahwa secara parsial variabel komunikasi pemasaran berpengaruh positif terhadap variabel keputusan membeli oleh masyarakat.

\section{PENUTUP}

\section{Kesimpulan}

Berdasarkan hasil analisis tentang pengaruh komunikasi pemasaran terhadap keputusan membeli buku oleh masyarakat pada Gramedia Banjarmasin Veteran maka dapat disimpulkan sebagai berikut:

1) Komunikasi pemasaran pada Gramedia Banjarmasin Veteran, yang termasuk kategori Baik sebanyak 48 orang (48,0\%), sedangkan yang kategori Cukup Baik sebanyak 42 orang $(42,0 \%)$, kategori Kurang Baik 6 orang $(6,0 \%)$, sedangkan yang kategori Sangat Baik sebanyak 3 orang $(3,0 \%)$ dan hanya 1 orang $(1,0 \%)$ yang termasuk kategori Tidak Baik. Hal ini menunjukan bahwa komunikasi pemasaran pada Gramedia Banjarmasin Veteran Baik.

2) Keputusan membeli pada Gramedia Banjarmasin Veteran, yang termasuk dalam kategori Sangat Baik sebanyak 34 orang $(34,0 \%)$, sedangkan kategori Baik sebanyak 23 orang (23,0\%), kategori Cukup Baik 17 orang $(17,0 \%)$, serta kategori Kurang Baik sebanyak 16 orang $(16,0 \%)$, dan ada 10 orang $(10,0 \%)$ yang termasuk kategori Tidak Baik. Hal ini menunjukan bahwa keputusan membeli buku oleh masyarakat pada Gramedia Banjarmasin Veteran Sangat Baik.

3) Pengaruh antara komunikasi pemasaran terhadap keputusan membeli buku oleh masyarakat menunjukkan bahwa setiap terjadi perubahan komunikasi pemasaran sebesar $1 \%$ pada nilai komunikasi pemasaran (X), maka nilai keputusan membeli (X) akan bertambah sebesar 0,112 (11,2\%). Berdasarkan nilai signifikansi untuk pengaruh variabel $\mathrm{X}$ tehadap variabel $\mathrm{Y}$ adalah sebesar 0,011 yang lebih kecil dari 0,05 sehingga dapat disimpulkan bahwa $\mathrm{H}_{1}$ dalam penelitian ini diterima. Selain itu, nilai $\mathrm{t}$ hitung adalah 2,580 sedangkan $\mathrm{t}$ tabel 1,984 karena $\mathrm{t}$ hitung $>\mathrm{t}$ tabel, sehingga dapat disimpulkan bahwa secara parsial variabel komunikasi pemasaran befpengarfined positif terhadap variabel keputusan mepdqulientoleh masyarakat pada Gramedia Banjarmasin Veteran.

T Sig.

\begin{tabular}{lll} 
4,703. Saran & 6,300 &, 000 \\
\hline
\end{tabular}

112 Dari kesimpulan, yang telah $_{\text {dikemukakan }}$
beberapa saran-saran yang perlu dijadikan pertimbangan yaitu:

1) Berdasarkan hasil analisis tingkat komunikasi pemasaran berada pada kategori Baik. Hal ini menandakan karyawan dalam memasarkan produknya memuaskan bagi konsumen. Oleh karena itu hendaklah Gramedia Banjarmasin Veteran agar dapat mempertahankan dan lebih baiknya lagi terus ditingkatkan komunikasi pemasarannya.

2) Berdasarkan hasil analisis tingkat keputusan membeli buku oleh masyarakat termasuk pada kategori Sangat Baik. Hal ini menandakan konsumen puas dalam hal karyawan melayani konsumennya untuk melakukan pembelian. Oleh karena itu, diharapkan Gramedia Banjarmasin Veteran agar terus dapat mempetahankan keputusan membeli buku oleh masyarakat pada Gramedia Banjarmasin Veteran.

3) Dengan adanya pengaruh antara komunikasi pemasaran terhadap keputusan membeli, hendaknya seluruh karyawan pada Gramedia Banjarmasin Veteran terus meningkatkan komunikasi pemasaran dalam melayani konsumennya, agar menciptakan keputusan membeli buku oleh masyarakat pada Gramedia Banjarmasin Veteran yang lebih optimal.

\section{REFERENSI}

BUKU

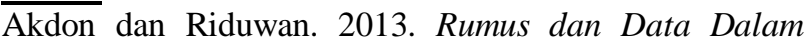
Analisis Statistika. Bandung : Alfabeta

Basu Swastha dan Irawan. 2000. Manajemen Pemasaran Modern. Edisi 2. Yogyakarta : Liberty.

Duncan, Tom. 2005. Principle Of Advertising and IMC. International Edition, Edisi Kedua. New York : McGrawHill.

Ghozali, Imam. 2005. Aplikasi Analisis Multivariate dengan SPSS. Semarang: Badan Penerbit UNDIP.

Hahn, Fred E. 2002. Beriklan dan Berpromosi Sendiri. Jakarta : PT. Gramedia. Pustaka Utama.

Ilham, Prisgunanto. 2006. Komunikasi Pemasran, Strategi, dan Taktik. Jakarta: Ghalia Indonesia.

J.Setiadi, Nugroho. 2008, Perilaku Konsumen. Jakarta: PT Kencana 
Margareta Krissa Delima dan Muhammad Agus Humaidi

MUTAKALLIMIN; Jurnal Ilmu Komunikasi

Vol 3 No 1 Mei 2020

Kotler, Philip. 2005. Manajemen Pemasaran. Jilid 1 dan 2. Jakarta : PT Indeks Kelompok Gramedia.

Kotler Philip dan Amstrong. 2008. Dasar-Dasar Pemasaran Edisi Ketiga. Jakarta : Erlangga.

Kotler, Philip and Kevin Lane Keller. 2008. Marketing Management $12^{\text {th }}$. Edisi 11. New Jersey : Prentice Hall.

2016. Marketing Management. Edisi 15. New Jersey: PrenticeHall Published.

Pace, R. Wayne. and Don, F. Faules. 2005. Komunikasi Organisasi: Strategi Meningkatkan Kinerja Perusahaan. Mulyana D, Kuswarno E, Gembirasari, penerjemaah. Mulyana D, editor. Bandung: PT. Remaja Rosdakarya.

Rahman, Arif. (2012). Strategi Dahsyat Marketing Mix for Small Business: Cara Jitu Merontokkan Pesaing. Cetakan Kesatu. Jakarta: Trans Media Pustaka.

Sugiyono. 2012. Metode Penelitian Pendidikan (Pendekatan Kuantitatif, Kualitatif dan R\&D). Bandung: ALFABETA.

Suharno. 2010. Dasar-Dasar Kebijakan Publik. Yogyakarta: UNY Press.

Tjiptono, Fandy. 2012. Strategi Pemasaran. Edesi 3. Yogyakarta : Andi.

Umar, Husain. 2005. Riset Pemasaran dan Perilaku Konsumen. Jakarta : PT. Gramedia Utama.

\section{JURNAL}

Bintoro, Ahyar Yuniawan dan I Made Sukresna. 2016. Pengaruh Komunikasi Pemasaran, Kepercayaan Merek dan Ekuitas Merek terhadap Keputusan Pembelian (Studi pada Produk Bubur Bayi Promina di Carrefour Wilayah Jakarta Selatan ). Jurnal Sains Pemasaran Indonesia. Vol. XV, No. 1

Dinda Anggraen. 2017. Pengaruh Komunikasi Pemasaran, Kelengkapan Produk dan Fasilitas terhadap Keputusan Pembelian pada Dealer Mpm Motor Pare. Simki-Economic. Vol. 01, No.09

Meriza Hendri. 2009. Pengaruh Komunikasi Pemasaran terhadap Keputusan Pembelian Teh Kotak Ultra Rasa Melati Oleh Remaja di Kota Bandung. Jurnal Manaj. 